Supporting Information

\title{
Targeted Phosphoinositides Analysis Using High Performance Ion Chromatography-Coupled Selected Reaction Monitoring Mass Spectrometry
}

Hilaire Yam Fung Cheung ${ }^{1,2,3}$, Cristina Coman ${ }^{1,4}$, Philipp Westhoff ${ }^{1}$, Mailin Manke ${ }^{5}$, Albert Sickmann ${ }^{1}$, Oliver Borst $^{5}$, Meinrad Gawaz ${ }^{5}$, Steve P. Watson ${ }^{2}$, Johan W.M. Heemskerk $^{3}$ and Robert Ahrends ${ }^{* 1,4}$

${ }^{1}$ Leibniz-Institut für Analytische Wissenschaften-ISAS-e.V., 44227 Dortmund, Germany ${ }^{2}$ Institute of Cardiovascular Sciences, Institute of Biomedical Research, College of Medical and Dental Sciences, University of Birmingham, Edgbaston, Birmingham, B15 2TT, UK

${ }^{3}$ Department of Biochemistry, Cardiovascular Research Institute Maastricht (CARIM), Maastricht University, 6229 ER Maastricht, The Netherlands ${ }^{4}$ Department of Analytical Chemistry, Faculty of Chemistry, University of Vienna, 1090 Wien, Austria ${ }^{5}$ Department of Cardiology and Cardiovascular Medicine, University of Tübingen, 72076 Tübingen, Germany.

\section{Table of contents:}

S-2 Figure S1. Fragment ion spectra of GroPInsP 2 .

S-3 Figure S2. Limit of detection and limit of quantification of Ptdlns $(3,4,5) \mathrm{P}_{3}$.

S-4 Figure S3. Comparison of amount of the identified phosphoinositides species with literature.

S-5 Figure S4. Structure of internal standard 16:0/16:0 Ptdlns(4,5)P2 $\alpha$-fluorovinylphosphonate (PtdIns(4,5)P2-FP).

S-6 Table S1. SRM transition list for the current study. 


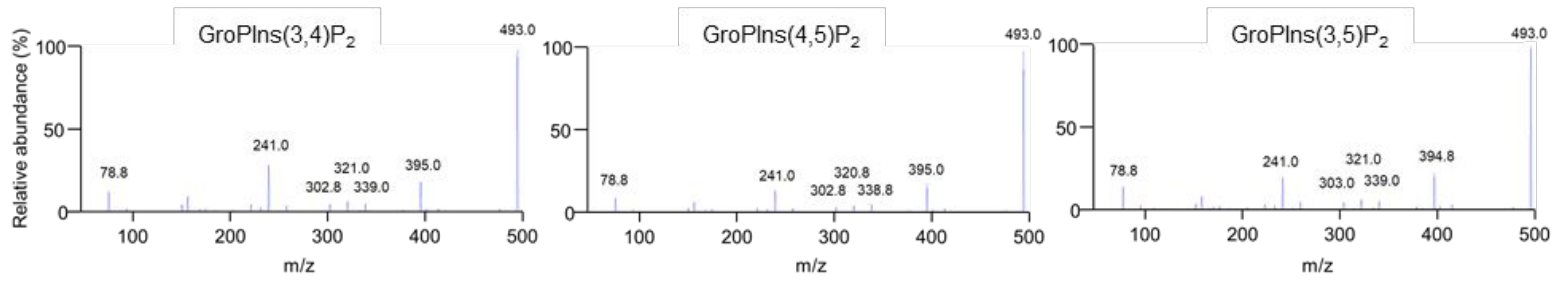

Figure S1. Fragment ion spectra of GroPIns $\mathrm{P}_{2}$. Phosphoinositides standard were extracted, deacylated into glycerolphosphoinositol phosphates and injected into ICMS/MS for analysis. The three GroPInsP $\mathrm{P}_{2}$ isomers had similar $\mathrm{MS}^{2}$ fragmentation patterns and fragment ion ratio at collision energy of $-27 \mathrm{eV}$. 


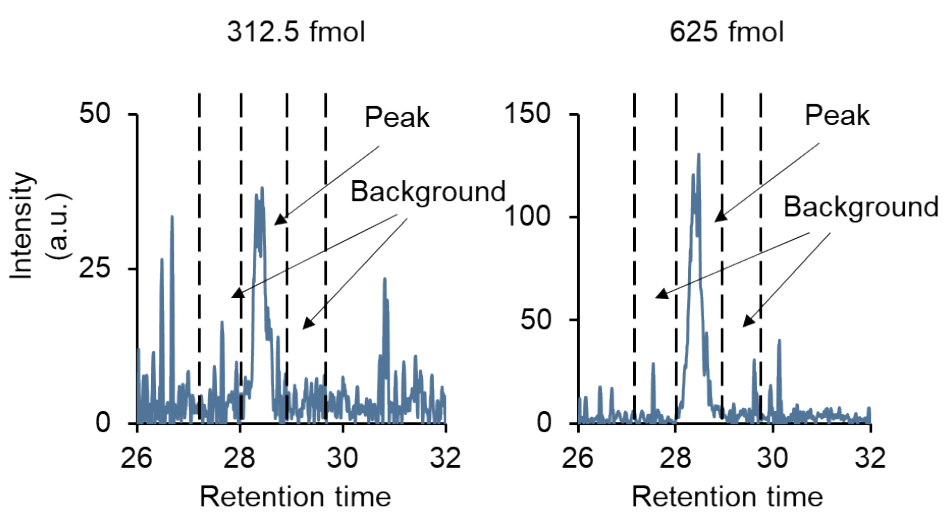

Figure S2. Limit of detection and limit of quantification of Ptdlns $(3,4,5) P_{3}$. The $\mathrm{XIC}$ of fragment ion of GroPIns $(3,4,5) \mathrm{P}_{3}$ at $321 \mathrm{~m} / \mathrm{z}$ where $3.125 \mathrm{pmol}$ and $6.25 \mathrm{pmol}$ Ptdlns $(3,4,5) \mathrm{P}_{3}$ standard were spiked into unstimulated human platelets extract, with $1 / 10$ of the sample injected into the column. Signal to noise ratio $=3.9$ for $312.5 \mathrm{fmol}$ and 12.5 for $625 \mathrm{fmol}$. 
A)

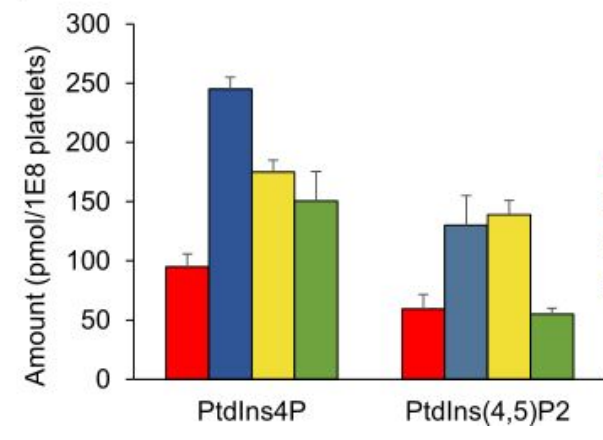

B)

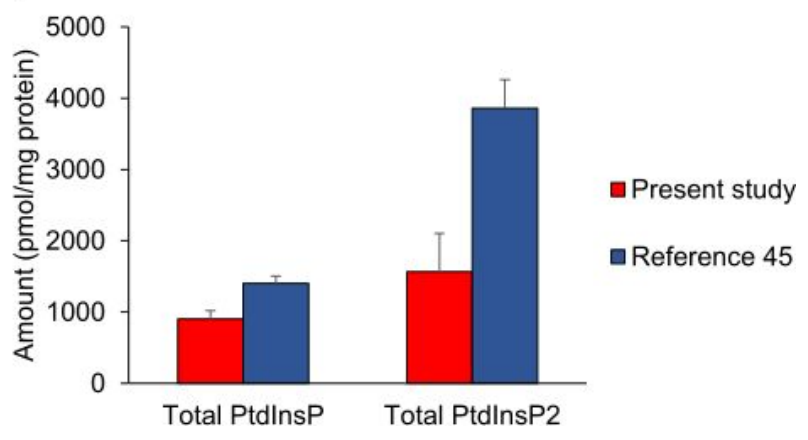

Figure S3. Comparison of amount of the identified phosphoinositides species with literature. The phosphoinositides quantified in $(A)$ unstimulated human platelets and $(B)$ hippocampus heavy membrane fraction were compared with previous reports. The results showed that the findings in the present study were consistent with previous studies. 


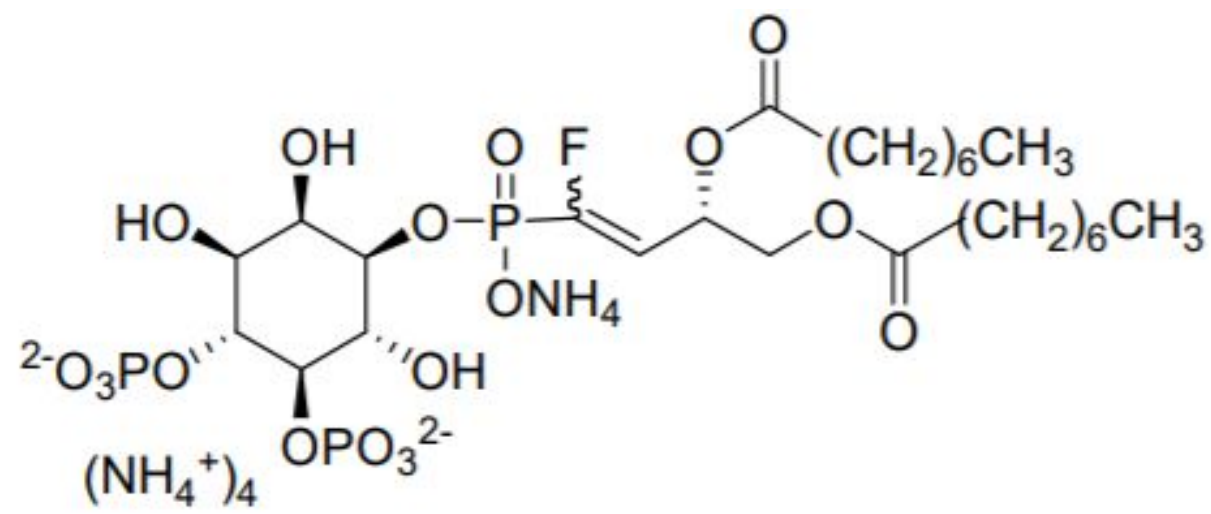

Figure S4. Structure of internal standard 16:0/16:0 Ptdlns(4,5)P2 $\alpha$-fluorovinylphosphonate (Ptdlns(4,5)P2-FP). 


\begin{tabular}{|c|c|c|c|c|}
\hline Species & $\begin{array}{c}\text { Q1 } \\
\text { Mass } \\
(\mathrm{m} / \mathrm{z})\end{array}$ & $\begin{array}{c}\text { Q3 } \\
\text { Mass } \\
(\mathrm{m} / \mathrm{z})\end{array}$ & $\begin{array}{l}\text { Collision } \\
\text { energy } \\
(\mathrm{eV})\end{array}$ & $\begin{array}{l}\text { Monitoring } \\
\text { window } \\
\text { (min) }\end{array}$ \\
\hline $\begin{array}{c}\text { Glycerophosphoinosito } \\
\text { phosphate } \\
\text { (GroPInsP) } \\
\end{array}$ & 413 & 241 & -27 & $11-17$ \\
\hline $\begin{array}{c}\text { Glycerophosphoinosito } \\
\text { bisphosphate } \\
\left(\mathrm{GroPInsP}_{2}\right) \\
\end{array}$ & 493 & 395 & -27 & $21-25$ \\
\hline $\begin{array}{c}\text { Glycerophosphoinosito } \\
\text { triphosphate } \\
\left(\mathrm{GroPlnsP}_{3}\right)\end{array}$ & 573 & 321 & -32 & $26-32$ \\
\hline $\begin{array}{c}\text { Glycerophosphoinositol (4 } \\
\text { bisphosphate } \alpha \text {-fluorovin } \\
\text { phosphonate } \\
\left(\text { GroPIns }(4,5) \mathrm{P}_{2}-\mathrm{FP}\right) \\
\end{array}$ & 509 & 411 & -27 & $21-25$ \\
\hline
\end{tabular}

Table S1. SRM transition list for the current study. SRM transition list used for glycerophosphoinositol phosphate analysis. 